\title{
Taş Kolonlarla İyileştirilen Yumuşak Zeminlerin Deprem Etkisi Altındaki Deplasman Analizi
}

\author{
Ferhat Şahinkaya $^{1^{*}}$, Gökhan Demir ${ }^{2}$ \\ 1* Yozgat Bozok Üniversitesi, Yozgat, Türkiye, (ORCID: 0000-0002-5534-7058), ferhat.sahinkaya@yobu.edu.tr \\ ${ }^{2}$ Ondokuz Mayı Üniversitesi, Samsun, Türkiye, (ORCID: 0000-0002-3734-1496), gokhan.demir@,omu.edu.tr
}

(2nd International Conference on Applied Engineering and Natural Sciences ICAENS 2022, March 10-13, 2022)

(DOI: $10.31590 /$ ejosat.1081844)

\begin{abstract}
ATIF/REFERENCE: Şahinkaya, F. \& Demir, G. (2022). Taş Kolonlarla İyileştirilen Yumuşak Zeminlerin Deprem Etkisi Altındaki Deplasman Analizi. European Journal of Science and Technology, (34), 317-320.

Öz

Şüphesiz depremler, tüm dünyada ve ülkemizde, önlem alınmadığı takdirde, can ve mal kayıplarına sebep olan önemli doğa olaylarından biridir. Bir yapıda taşıyıcı sistem ne kadar sağlam olursa olsun, deprem sırasında zeminin taşıma gücünün azalması sebebiyle meydana gelen aşırı deplasman durumunda, yapının zarar görmemesi mümkün olmayacaktır. Bu çalışmada, bir derin iyileştirme yöntemi olan taş kolon yöntemi kullanılarak, Plaxis 2D sonlu elemanlar programı vasıtasıyla oluşturulan zemin modelleri ile deprem analizleri yapılmıştır. Analizlerde 24 Ocak 2020 tarihinde Türkiye'nin Elazığ şehrinde meydana gelen ve büyük kayıplara sebep olan depremin ivme kaydı kullanılmıştır. Taş kolonsuz zemin ile yapılan dinamik analizler sonrasında zemine, $60 \mathrm{~cm}$ çapında, taş kolonların merkezleri arası mesafenin (s) taş kolon çapına (D) oranı s/ $\mathrm{D}=2$ olacak şekilde taş kolon uygulaması yapılmıştır. Daha sonra taş kolon malzemesinin içsel sürtünme açısı $(\phi) 35^{\circ}, 40^{\circ}, 45^{\circ}$ olarak değiştirilerek, dinamik analizler tekrar edilmiştir. Sonuç olarak deprem sırasında taş kolonsuz ve taş kolonlu zemin modelleri için zeminin dinamik zamana bağlı deplasman değişimleri incelenmiştir. Taş kolonların deprem sırasında meydana gelebilecek deplasmanları engellediği görülmüştür.
\end{abstract}

\section{Displacement Analysis of Soft Soils Improved with Stone Columns Under the Effect of Earthquake}

\begin{abstract}
Undoubtedly, earthquakes are one of the important natural events that cause loss of life and property all over the world and in our country, unless precautions are taken. No matter how strong a structure is, it will not be possible for the structure not to be damaged in case of excessive displacement due to the decrease in the bearing capacity of the soil during an earthquake. In this study, soil models improved with stone columns, which is a deep remediation method, were created using the Plaxis 2D finite element program and dynamic analyzes were performed. In the analysis, the acceleration record of the earthquake that occurred in Elazı $\breve{g}$, Turkey on January 24, 2020 and caused great losses was used. After the dynamic analyzes with the stone columnless soil, a stone column was applied to the soil with a diameter of $60 \mathrm{~cm}$, with the ratio of the distance between the centers of the stone columns (s) to the diameter of the stone columns (D) being s/D=2. Then, the internal friction angle $(\phi)$ of the stone column material was changed to $35^{\circ}, 40^{\circ}, 45^{\circ}$ and dynamic analyzes were repeated. As a result, dynamic time-dependent displacement changes of the soil were investigated for the soil models with and without stone columns during the earthquake. It has been observed that the stone columns prevent the displacements that may occur during the earthquake.
\end{abstract}

Keywords: Soft soil, Stone columns, Earthquake effect, Displacement, Finite elements

* Corresponding Author: ferhat.sahinkaya@yobu.edu.tr 


\section{Giriş}

Geçmişten günümüze kadar yapılan birçok çalışmaya bakıldığında, depremin zeminler üzerindeki etkisinin yeni yeni incelenmeye başlandığı görülmektedir. Bu durumun ana sebebi, zemin alanında nonlineer analiz yapabilen bilgisayar yazılımlarının son yıllarda kayda değer bir şekilde geliştirilmiş olmasıdır. Bu çalışmada, özellikle geoteknik alanında kendini ispatlamış ve birçok firma tarafından kullanılmakta olan Plaxis 2D sonlu elemanlar yazılımının dinamik modülü kullanılmıştır. Programda taş kolonlu ve taş kolonsuz olarak zemin modelleri oluşturulduktan sonra, 24 Ocak 2020 tarihinde Türkiye'nin Elazı ̆̆ şehrinde meydana gelen depremin ivme kaydı kullanılarak, her iki model tabanından deprem etkisi uygulanmıştır. Her iki zemin modeline simetrik bir şekilde yerleştirilen 4 metre genişliğindeki plaka temelin orta noktası işaretlenerek, bu noktada deprem sırasında y yönündeki hareketin değişim grafikleri oluşturulmuştur.

Sonlu elemanlar kullanılarak taş kolonlarla iyileştirilen zeminlerin yarı-statik analizlerinin yapıldığ 1 bir çalışmada, taş kolonların çap, derinlik, aralık ve malzeme parametrelerinin taşıma gücü ile temelde meydana gelen deplasmana ne kadar etki ettiği kapsamlı bir şekilde incelenmiştir. Özellikle taş kolon çapının ve taş kolon malzemesinin içsel sürtünme açısının artışıyla, taşıma gücünde meydana gelen kayıplar ve temelde meydana gelen düşey yönlü deplasmanlar kayda değer bir şekilde azalmıştır (Sahinkaya vd., 2017). Sonlu elemanlar programlarıyla yapılan dinamik çalışmaların yanı sıra laboratuvar ortamında oluşturulan modeller üzerine tekrarlı yük uygulanarak da zeminin sismik yüke maruz kaldığı çalışmalarda bulunmaktadır. Örneğin belirli boyutlarda laboratuvar ortamında oluşturulmuş laminer kutu kullanılarak, geogrid sargılı taş kolonlarla iyileştirilen zeminin tekrarlı yükler altındaki davranışı incelenmiştir. Deneyler sonucunda sargılı taş kolonların, sargısız taş kolonlardan daha az miktarda oturduğu görülmüştür (Cengiz ve Güler, 2017). Yine sonlu elemanlar programıla yapilan bir sayısal analiz çalışmasında kuru kum üzerine inşa edilen sığ bir temelin sismik oturmasını araştırmak için 105 adet sonlu elemanlar modeli oluşturulmuştur. Çalışmada temel üzerine uygulanan yükün miktarı, kumun yoğunluğu, model boyutları, mesh sıkılığı vb. parametrelerin sismik oturmaya ne kadar etki ettiği kapsamlı bir şekilde incelenmiştir. Analizlerden elden edilen sonuçlara göre, temel üzerine uygulanan yükün ve en yüksek yer ivmesinin artırılması ile oturmaların önemli ölçüde $\operatorname{arttığ~} 1$ görülmüştür (Alzabeebee, 2020).

\section{Zemin modelinin oluşturulması}

Dinamik analizlerde kullanılacak model boyutunun seçimi, sonucun gerçeğe daha yakın olması için büyük önem arz etmektedir. Bu noktada ana kaya derinliği birçok farklı çalışma da 30-40 metre aralığında seçilmiş olduğundan model derinliği 30 metre olarak belirlenmiştir (Zhang ve Chen, 2018; Zhang ve Liu, 2020; Alzabeebee, 2019; Meena ve Nimbalkar, 2019). Ayrıca model üzerine tanımlanan ağ (mesh) yoğunluğunun ve model genişliğinin sonuçlara doğrudan etki ettiği yapılan diğer çalışmalarda da görülmektedir. $\mathrm{Bu}$ kapsamda yapılmış bir çalışmada model genişliğinin 40 metrenin altında seçilmesi durumunda sonuçların azalarak gerçeklikten uzaklaştığı, 40 metre ve üzerinde seçilen genişliklerde ise sonuçların değişmediği gözlemlenmiştir (Alzabeebee, 2020). Bu ve buna benzer literatürde yer alan diğer çalışmalarda incelenerek model genişliği 80 metre derinliğinin ise 12 metrelik kil, 18 metrelik kum olmak üzere toplamda 30 metre olarak belirlenmiştir. Kil tabakasının kalınlığı, taş kolon uygulama derinliği de göz önünde bulundurularak, plaka temel genişliğinin üç katı (3B) olarak seçilmiştir. Taş kolonsuz zemin modeli Şekil 1'de görülmektedir.

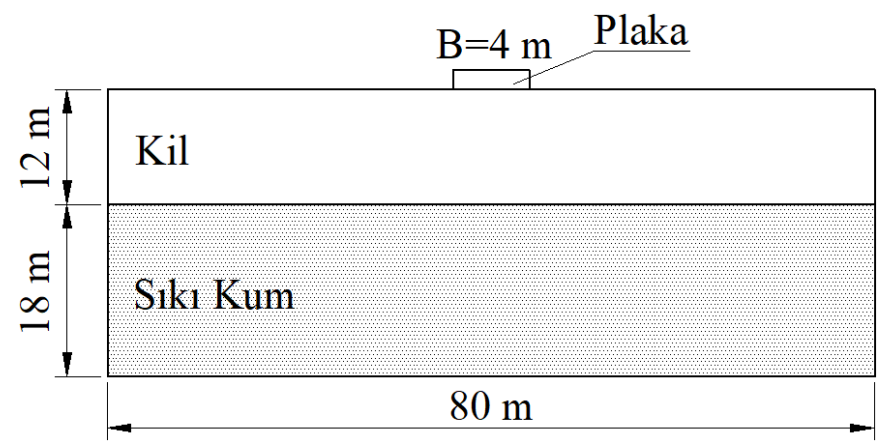

Şekil 1. Taş kolonsuz zemin modeli

Taş kolonsuz zemin modeli ile yapılan dinamik analizler tamamlandıktan sonra zemine, $60 \mathrm{~cm}$ çapında, temel genişliğinin üç katı derinliğinde ve taş kolon malzemesinin içsel sürtüne açısı ( $\phi) 35^{\circ}, 40^{\circ}, 45^{\circ}$ olacak şekilde taş kolon uygulaması yapılmıştır. Taş kolonlu zemin modeli örneği Şekil 2'de görülmektedir.

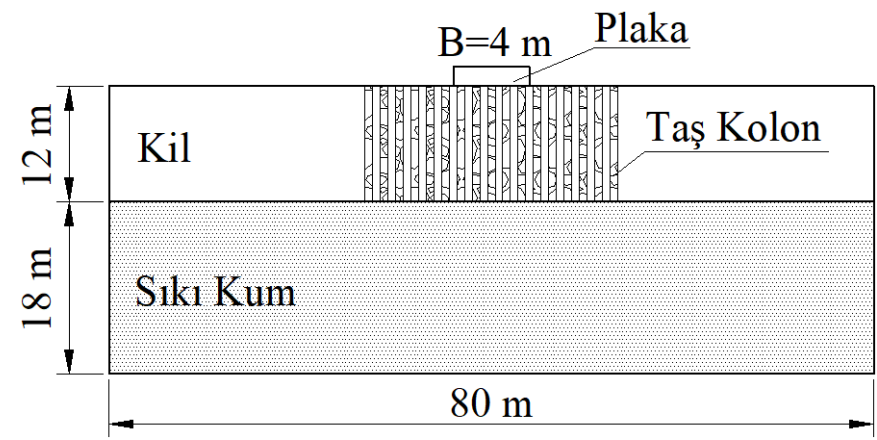

Şekil 2. Taş kolonlu zemin modeli

Çalışmada zemin modelleri deprem etkisinde analiz edileceğinden, modellerde kullanılacak malzeme özellikleri de büyük önem arz etmektedir. $\mathrm{Bu}$ kapsamda literatürde yapılan birçok çalışmada da dinamik analiz söz konusu olduğunda, histeritik sönümleme özelliğinide içinde barındırması sebebiyle, HSsmall (Hardening Soil Model with Small-Strain Stiffness) modelin sıklıkla tercih edildiği görülmektedir (Raikar, 2016). Yapılan bu çalışmada da kullanılan yumuşak kil, sıkı kum ve taş kolon malzemeleri HSsmall modeli kullanılarak oluşturulmuştur. Analizlerde kullanılan yumuşak kil, sıkı kum ve taş kolonun malzeme özellikleri Tablo 1'de verilmiştir. 
Tablo 1. Malzeme özellikleri

\begin{tabular}{|c|c|c|c|}
\hline Malzeme & Kil & Sıkı kum & Taş kolon \\
\hline Drenaj Durumu & Drenajsiz & Drenajl1 & Drenajl1 \\
\hline Kuru Birim Hacim Ağırlık, $\gamma \mathrm{k}\left(\mathrm{kN} / \mathrm{m}^{3}\right)$ & 15 & 20 & 19 \\
\hline Suya Doygu Birim Hacim Ağırlık, $\gamma \mathrm{d}\left(\mathrm{kN} / \mathrm{m}^{3}\right)$ & 17 & 20 & 22 \\
\hline Permabilite, kx,ky (m/gün) & $1 \times 10^{-8}$ & 10 & 100 \\
\hline $\begin{array}{l}\text { Drenajlı üç eksenli deneylerle elde edilen sekant rijitliği, } \\
\mathrm{E}_{50}{ }^{\text {ref }}\left(\mathrm{kN} / \mathrm{m}^{2}\right)\end{array}$ & 4000 & $60 \times 10^{3}$ & $27 \times 10^{3}$ \\
\hline $\begin{array}{l}\text { Drenajlı odömetre deneyleriyle elde edilen tanjant } \\
\text { rijitliği, } E_{\text {oed }}{ }^{\text {ref }}\left(\mathrm{kN} / \mathrm{m}^{2}\right)\end{array}$ & 3000 & $60 \times 10^{3}$ & $27 \times 10^{3}$ \\
\hline Elastik yükleme/boşaltma rijitliği, $\mathrm{E}_{\mathrm{ur}}^{\text {ref }}\left(\mathrm{kN} / \mathrm{m}^{2}\right)$ & 10000 & $180 \times 10^{3}$ & $70 \times 10^{3}$ \\
\hline Zeminin gerilme bağımlı sertliği, power (m) & 1 & 0.4 & 0.5 \\
\hline Poisson Oran1, $v$ & 0.2 & 0.15 & 0.3 \\
\hline Kohezyon, c, $\left(\mathrm{kN} / \mathrm{m}^{2}\right)$ & 15 & 1 & $1 \times 10^{-8}$ \\
\hline İçsel Sürtünme Açısı, $\phi\left(^{\circ}\right)$ & 1 & 40 & $35 / 40 / 45$ \\
\hline Sükunetteki Toprak Basınc1 Katsayısı, $\mathrm{K}_{0}$ & 0.966 & 0.344 & 0.32 \\
\hline Maksimum kayma modülü, $\mathrm{G}_{0 \mathrm{ref}}$ & $3.3 \times 10^{4}$ & $1 \times 10^{5}$ & $1 \times 10^{5}$ \\
\hline Kayma birim deformasyonu, $\gamma_{07}$ & $0.2 \times 10^{-3}$ & $0.15 \times 10^{-3}$ & $1 \times 10^{-3}$ \\
\hline
\end{tabular}

\section{Sonlu elemanlar analizi}

Deprem etkisinde deplasman analizleri ilk olarak taş kolonsuz zemin modeli ile yapılmıştır. Elazı ğ depremi toplam 55,5 saniye sürmüş olup ilk 25 saniye sonrasında deplasmanda bir değişim olmadığı için analizlerde ivme-zaman kaydının ilk 25 saniyesi kullanılmıştır. Elazığ depremine ait ivme-zaman grafiği Şekil 3 'te görülmektedir.

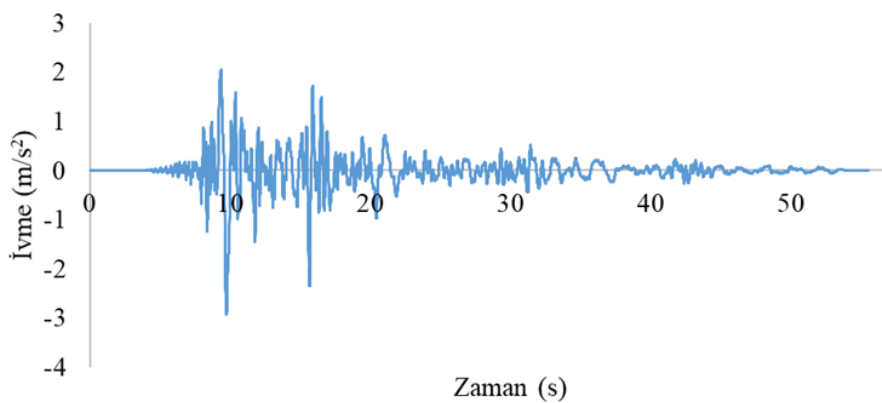

Şekil 3. Elazı̆̆ depremi ivme-zaman grafiğgi

Kohezyon değeri $15 \mathrm{kN} / \mathrm{m}^{2}$ olan taş kolonsuz ve taş kolonlu zemin modelleri ile yapılan deplasman analizlerinde, taş kolonsuz zeminin nihai taşıma gücü değeri olan $88,67 \mathrm{kN} / \mathrm{m}^{2}$ 'lik yayılı yük kullanılmıştır. Bu yük etkisinde temelin orta noktasında deprem sırasında meydana gelen deplasman değişimleri, taş kolonsuz zemin modeli için Şekil 4'te, taş kolonlu zemin modelleri için ise içsel sürtünme açısındaki değişime bağlı olarak $\left(35^{\circ}, 40^{\circ}, 45^{\circ}\right)$ Şekil 5 'te verilmiştir.

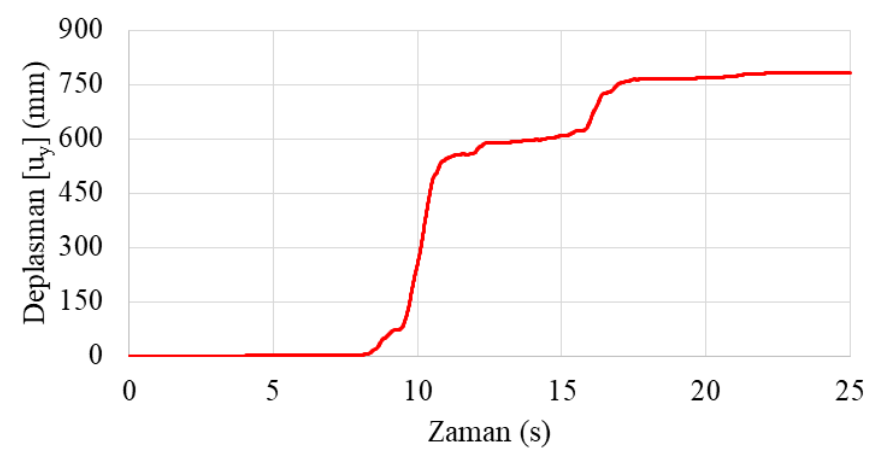

Şekil 4. Taş kolonsuz zeminin deprem etkisinde deplasman değişimi

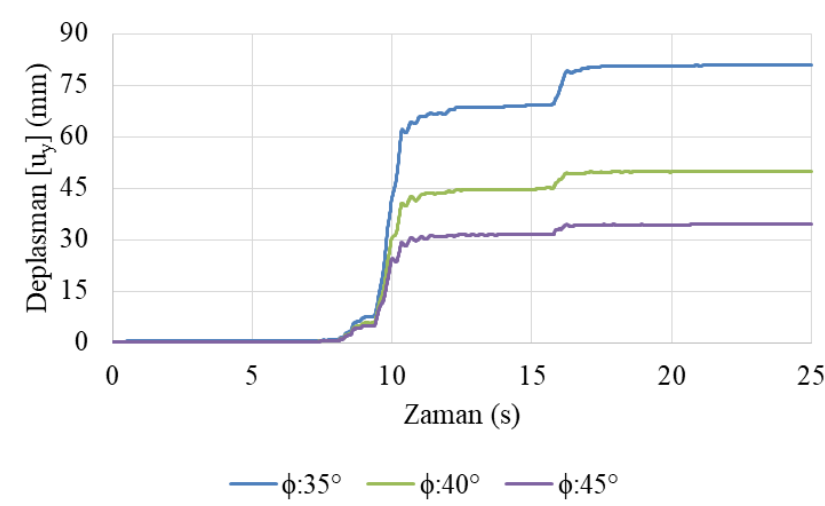

Şekil 5. Taş kolonlu zeminin deprem etkisinde deplasman değişimi

\section{Bulgular}

Elazı̆̆ depremi sonrasında taş kolonsuz ve taş kolonlu zemin modellerinde, temelin orta noktasında meydana gelen deplasmanlar Tablo 2'de verilmiştir.

Tablo 2. Deprem sonrası deplasmanlar

\begin{tabular}{|c|c|c|c|c|}
\hline $\begin{array}{l}\text { Çap } \\
\text { (D) }\end{array}$ & $\begin{array}{l}\text { Aralik } \\
(\mathrm{s} / \mathrm{D})\end{array}$ & $\begin{array}{c}\text { İçsel } \\
\text { Sürtünme } \\
\text { Açısı }(\phi)\end{array}$ & $\begin{array}{c}\text { Deplasman } \\
\text { (mm) }\end{array}$ & $\begin{array}{c}\text { Deplasman } \\
\text { Azalma } \\
\text { Miktarı }\end{array}$ \\
\hline \multirow{3}{*}{$\begin{array}{l}60 \\
\mathrm{~cm}\end{array}$} & \multirow{3}{*}{$\mathrm{s} / \mathrm{D}=2$} & $35^{\circ}$ & 80,85 & $\% 90$ \\
\hline & & $40^{\circ}$ & 49,98 & $\% 94$ \\
\hline & & $45^{\circ}$ & 34,41 & $\% 96$ \\
\hline
\end{tabular}

Taş Kolonsuz Zemin Modeli 781,40

Tablo 2'de yer alan deplasman miktarları incelendiğinde, deprem sonrasında temel plakasının orta noktasında taş kolonsuz zemin modelinde $781,40 \mathrm{~mm}$ 'lik deplasman meydana gelirken, $35^{\circ}, 40^{\circ}, 45^{\circ}$ lik içsel sürtünme açılarına sahip taş kolon 
malzemeleri ile iyileştirilen zemin modellerinde sırasıyla 80,85 $\mathrm{mm}, 49,98 \mathrm{~mm}$ ve $34,41 \mathrm{~mm}$ 'lik deplasmanlar meydana gelmiştir.

\section{Sonuçlar ve öneriler}

Elazı $\breve{g}$ depremi etkisinde yapılan deplasman analizlerinde, taş kolonsuz zemin modelinde meydana gelen deplasman miktarı, kabul edilebilir sınırların oldukça dışında kalmıştır. Bu durum yumuşak zeminlerin iyileştirilmesinin gerekliliğini açıkça göstermektedir. Taş kolonlarla iyileştirilen modeller üzerinde yapılan analizlerde ise deplasman miktarları $10 \mathrm{~cm}$ 'nin altına düşerek kabul edilebilir sınırlar içerisinde kalmıştır. Taş kolonsuz zemine göre deprem sonrası meydana gelen deplasmanlar ortalama \%93 azalmıştır. Taş kolon malzemesinin içsel sürtünme açısındaki artışa bağlı olarak $\left(35^{\circ}, 40^{\circ}, 45^{\circ}\right)$ deplasman miktarları sırasıyla \%90, \%94 ve \%96 azalmıştır. Sonuç olarak taş kolonlar deprem sırasında meydana gelen ve yapının zarar görmesine sebep olabilecek ölçüdeki deplasman değerlerini, kabul edilebilir seviyelere kadar azalmıştır. Yapılan bu çalışma, özellikle yumuşak zeminlerin yer aldığı ve deprem riski bulunan bölgelerde, taş kolonlar gibi derin iyileştirme yöntemlerinin kullanılmasının, can ve mal kayıplarının engellenmesi konusunda hayati önem taşıdığını göstermektedir.

\section{Kaynakça}

Alzabeebee S., Seismic response and design of buried concrete pipes subjected to soil loads. Tunn Undergr Sp Technol 93:103084, 2019.

Alzabeebee, S., Seismic settlement of a strip foundation resting on a dry sand. Natural Hazards, 103, 2395-2425. University of Al-Qadisiyah, Al-Qadisiyah, 2020.

Cengiz C. ve Güler E., Deprem Yüklerine Maruz Kalmış Geosentetik Donatılı Taş Kolonların Yük Taşıma Performansları ve Deformasyon Modları, Yedinci Ulusal Geosentetikler Konferansı, Boğaziçi Üniversitesi, İstanbulG. R. Faulhaber, "Design of service systems with priority reservation," in Conf. Rec. 1995 IEEE Int. Conf. Communications, pp. 3-8 2017.

Meena NK. and Nimbalkar S., Effect of water drawdown and dynamic loads on piled raft: two-dimensional finite element approach. Infrastructures 4(4):75, 2019.

Raikar P. Modelling Soil Damping for Suction Pile Foundations. Master of Science Thesis, Delft University of Technology., 2016

Sahinkaya F., Vekli, M. and Cadir C.C., Numerical analysis under seismic loads of soils improvement with floating stone columns. Natural Hazard, Volume 88, Issue 2, pp 891-917, 2017.

Zhang J., Chen Y., Experimental study on mitigations of seismic settlement and tilting of structures by adopting improved soil slab and soil mixing walls. Sustainability 10(11):4069, 2018.

Zhang L., Liu Y., Numerical investigations on the seismic response of a subway tunnel embedded in spatially random clays. Undergr Sp 5(1):43-52, 2020. 